\section{The sky is the limit}

\section{Washington}

How much is too much for the Superconducting Super Collider (SSC)? At an estimated $\$ 8,000$ million earlier this year, the planned particle accelerator's cost was already larger than the Gross National Product of two-thirds of the world's nations, the entire US yearly spending on health research and the cost of all current European particle accelerators combined. Now a Department of Energy (DOE) advisory panel says that the project will need still more - difficulties with the SSC's magnets and the extra costs of any cialays in obtaining funds from Congress may drive the total price to $\$ 8,600$ million by its completion in 1998 , the panel said last week.

The SSC cost estimate panel, comprising members of DOE's High Energy Physics Advisory Panel (HEPAP), was the most pessimistic of three groups that have re-examined the project's financial prospects for DOE. An internal team of DOE experts puts the cost at $\$ 8,300$ million. And an estimate by University Research Associates (URA), the contractor which will actually build the SSC, promises to finish the project at the bargain price of $\$ 7,840$ million. A review by a fourth group, made up of outside financial experts, is still uncompleted. DOE will compare all four estimates and submit a final report to Congress on 17 August.
The chief concern seems to be the schedule and technical challenges of building the superconducting magnets. "The project has been planned on an extremely optimistic schedule, with every event being 'head-to-tail' with others ... [S] [Sch an approach results in an unrealistically low estimate, which will inevitably be overrun", HEPAP warned. The panel also noted that the SSC has had difficulty attracting staff.

Beyond technical problems looms the very real possibility that Congress, squeezed by deficit reduction and still uneasy about the scientific arguments behind a 54-mile superconducting accelerator, may cut the project's funding at some time during the next eight years. Moore said that a congressional funding delay could add over $\$ 50$ million a month to the SSC's final cost. The HEPAP panel says that schedule delays are likely to contribute $\$ 300$ million to the overrun.

HEPAP also recommended that another $\$ 300$ million - which would raise the total cost to $\$ 3,900$ million - should be budgeted to build two large detectors that are part of the original SSC plan. But rather than raise the cost further, SSC officials have decided to drop the two large detectors for the time being. Two less expensive detectors - one medium, the other small - should be sufficient for the early years, says acting project mana-

\section{Keeping it clean for science}

\section{Säo Paulo}

THE twenty-first meeting of the Scientific Organization on Antarctic Research (SCAR) ended here last week with the addition of four new full members Spain, South Korea, Finland and Holland - and a new associate member Colombia - bringing the total membership to 29 countries.

The scientific focus of the meeting was the effort to integrate Antarctic research with global scientific concerns, particularly climate change. The threat to the region's environment was also a theme of the meeting: "The environment is not one major issue, it is the major issue", said Brazilian geologist Antonio Carlos Rocha-Campos, executive secretary of SCAR and chairman of the meeting.

Dealing with the waste produced by an Antarctic population that can reach 4,000 in the summer months (December to March) has become one of the greatest environmental concerns. SCAR has produced a rulebook on waste management, but enforcing it is another matter. Not all of the 50 Antarctic stations have the requisite waste-disposal technology, but
Rocha-Campos diplomatically refused to name the worst offenders. Inspections conducted by Greenpeace, however, have documented open-air trash burning at the Chinese, Chilean, Argentine, Uruguayan, US and Soviet bases.

Tourism is also becoming a headache, both as an additional source of pollution and because of disruption to the scientific activities of the stations. SCAR, an advisory body to the Antarctic Treaty nations which coordinate research efforts, considers tourism a "legitimate activity" when properly ordered, but scientists are finding it troublesome.

SCAR has no power to enforce its recommendations but has, for example, suggested that unnecessary duplication of activities should be avoided, especially in crowded areas such as the Antarctic Peninsula and the nearby King George Island. Crowding exacerbates environmental problems, but the mood of the SCAR meeting was that it is the responsibility of scientists to deal with problems that will ultimately disrupt the science they have come to Antarctica to conduct.

Ricando Bonalume Neto ger Ted Kozman. Hc says that there may not be enough physicists available to justify the operation of larger detectors when the SSC begins operation at the end of the decade. Expansion room will be built into the SSC to allow larger detectors to be installed later when the demand rises, Kozman says.

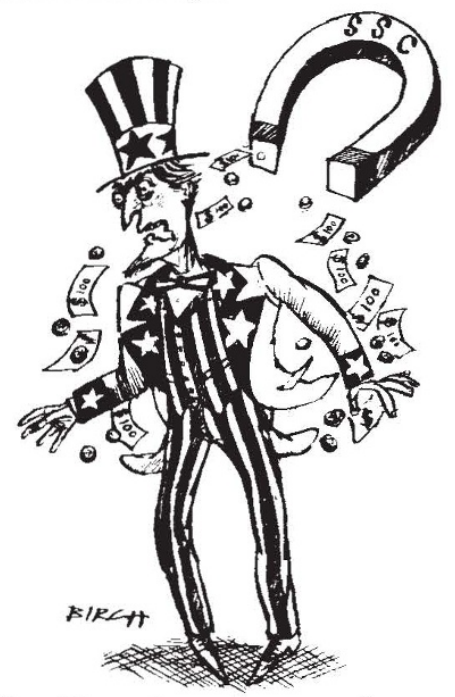

Speaking at a press conference last week, DOE deputy secretary W. Henson Moore said that the department intends to go to Congress with the URA figures, rather than the higher estimates. "We're going to hold the contractor to $\$ 7.8$ billion and to finish by $1998^{\prime}$, he said. Although there is no penalty if URA is then forced to raise the cost, Moore said the contractor would have to document the need and get DOE approval. Submitting one of the higher estimates to Congress, Moore said, would only be sending the signal that congressional and technical delays are anticipated and compensated for. "If we were to take any other position, we'd be telling the contractor, 'We expect delays, don't worry about it'," he said. So far this year, Congress has treated the project relatively well, granting the full DOE request of $\$ 318$ million for 1991. But until legislators trim spending across the board later this year to reduce the federal deficit, final budgets for all projects - including the SSC - will remain at risk.

Moore also announced the release of the formal request for proposals to build the superconducting magnets. Because the magnets will represent a substantial advance in technology and engineering, the companies or countries that provide them stand to become world leaders in the fledgling superconductor industry. Although DOE's offer stipulates that at least 50 per cent of the contract must go to US industry, companies from foreign countries may bid on the other half of the contract, perhaps as part of an 'in kind' contribution from their nation's government. So far, only Korea and India have expressed interest in contributing to the project.

G. Christopher Anderson 